\title{
Aircraft System Design Graduate Curriculum: A Lifecycle Focus
}

\author{
Earll M. Murman, Paul A. Lagacé \\ Department of Aeronautics and Astronautics, and \\ Engineering Systems Division \\ Massachusetts Institute of Technology \\ Cambridge, MA 02139
}

\begin{abstract}
Aircraft system design encompasses technical, social and lifecycle topics, and is suitable for graduate studies at the masters level and beyond. Several degree programs in MIT's School of Engineering offer opportunities for students seeking subjects and degrees in this area. These programs are summarized, and one subject on Aircraft Systems Engineering is introduced as an illustration of content and pedagogy addressing lifecycle topics. Based upon several years of experience of participation in these programs and in offering curriculum, the authors put forward seven observations to stimulate further dialog and progress on this topic.
\end{abstract}

\section{Introduction}

Undergraduate subjects on aircraft design have been taught for many years in aeronautical or aerospace engineering departments, often as a capstone subject. A key pedagogical objective is teaching tradeoffs among disciplinary needs to meet system-level requirements. The focus is usually on preliminary design or prototyping. Aircraft, however, are complex systems comprising many subsystems, and usually represent only one element in an air transportation, air defense, or other system of systems. In the current and future marketplace, successful aircraft must deliver best lifecycle value, i.e. they must meet stakeholder expectations for lifecycle costs, availability, and performance. And aircraft must meet stringent safety and environmental criteria. The multitude of factors that influence aircraft design go beyond what can be addressed in one course at the undergraduate level and open opportunities for graduate level curriculum for aircraft system $^{\mathrm{a}}$ design.

Aircraft systems encompass a wide spectrum of technical, social and lifecycle factors with interrelationships amongst them ${ }^{1}$. Aeronautical engineers are familiar with the many technical factors, ranging in scale from individual parts or lines of code through major components and subsystems to the aircraft system and beyond to the system of systems level. Taking into account all these technical elements and their interfaces, interactions and interdependencies in the design of an aircraft is a major challenge. The challenge is intensified when one realizes that modern aircraft have lifecycles measured in many decades. To cite just two examples from the Appendix, the DC-9 family of aircraft will have been in service with major airlines for 45 years and the B-52H with the U.S. Air Force for at least 75 years when they are finally phased out.

\footnotetext{
a Usage of the word "system" or "systems" varies within the field. For some, the plural version refers to the entire aircraft and all is subsystems, while for others it refers only to the subsystems. Both singular and plural forms are used in this paper, somewhat interchangeably, to represent the entire aircraft as a system. 
Lifecycle phases proceed from conceptual design through preliminary and detailed design, to production, testing, operation and maintenance, and finally to refurbishment, upgrade or disposal. Addressing the requirements for each of these phases - sometimes called "Design for X", or DFX, - is a major part of aircraft design. Since decisions made in early design phases lock in $60-80 \%$ of the lifecycle costs ${ }^{2}$, DFX is as important as design for performance in determining product success. Equally important is the spectrum of social factors influencing aircraft design, ranging from human-centered engineering related to pilot-aircraft interface as well as passengers, maintainer and assembler ergonomics, through enterprise-level factors such as integrated product teams, supply chains and management systems, up to geopolitical societal factors such as employment, environmental regulation, and international trade. Social factors also dictate a need to take into account the different perspectives of the multiple stakeholders involved in the overall system in which aircraft are involved. Addressing all these factors in aircraft design goes beyond the traditional boundaries of aerospace engineering and requires the engagement of management and social sciences faculty.

A comprehensive curriculum for aircraft system design addressing all the above topics is appropriate for master-level degree programs in aerospace engineering and related fields such as systems engineering. Clearly the scope of this is well beyond a single subject. It needs to encompass a number of core and elective subjects together with application through thesis or practicum studies. In this paper, the authors summarize curriculum that has evolved over the past 15 years in MIT's School of Engineering, in many cases in cooperation with colleagues from MIT's Sloan School of Management. Based on experience acquired, observations are made that may be generally relevant for others who might be considering the development of such curriculum. This paper particularly focuses on the lifecycle factors addressed in the curriculum, touching only lightly on the technical, social, and other associated factors.

\section{MIT Curriculum}

The MIT graduate curriculum on Aircraft System Design is accessible through several master degree programs, each tailored to a different student audience. The Department of Aeronautics and Astronautics ${ }^{3}$ (Aero-Astro) offers a Master of Science (SM) degree targeted at new or recent undergraduates seeking graduate aerospace engineering studies to enter industry or government employment, or to pursue doctoral degree studies. The Engineering Systems Division ${ }^{4}$ (ESD) offers a joint engineering and management SM degree in System Design and Management ${ }^{5}$ (SDM) targeted at students with 3 to 5 or more years of engineering work experience who seek advanced studies in system engineering and management in preparation for a career in technical leadership positions in industry and government. The School of Engineering, through ESD, and the Sloan School of Management jointly offer the Leaders for Manufacturing ${ }^{6}$ (LFM) Program, resulting in dual SM degrees in engineering and management, to recent graduates or candidates with work experience, in preparation for a career in Manufacturing - with the "Big M" indicating the inclusion both up and downstream lifecycle phases. Both the SDM and LFM programs result in what are considered as professional masters degrees, and normally students do not proceed to doctoral studies. However, students are well prepared to apply to the ESD PhD program if they seek doctoral level studies. Further description of each of these programs is given in the following paragraphs, after which some of the specific subjects supporting these degrees are introduced, and one is covered in some detail. 
The overall objective of the Aero-Astro program in Aircraft Systems Engineering is to provide students with a foundational understanding of the systems engineering/architecture process and methodologies required to transform fundamental technical, economic, and societal requirements into an integrated product solution. Figure 1 portrays the high level structure of the program comprising four basic components: (1) two subjects in systems engineering and architecting (Aircraft System Engineering, Air Transportation System Architecting); (2) two subjects in mathematics (recommended to be in Probability and Statistics, and Optimization); (3) two or more electives to be drawn from areas of airframe and propulsion technologies, aircraft information systems, systems design, and enterprise processes; and (4) a research thesis that ideally encompasses and integrates material from the subjects. To provide context for their studies, students are also expected to gain exposure to the practice of systems engineering in a summer internship or prior industrial experience. The program is loosely structured (in contrast to the following two programs) with students developing their own learning objectives and course of study. Further descriptions of this program can be found in Reference 7.

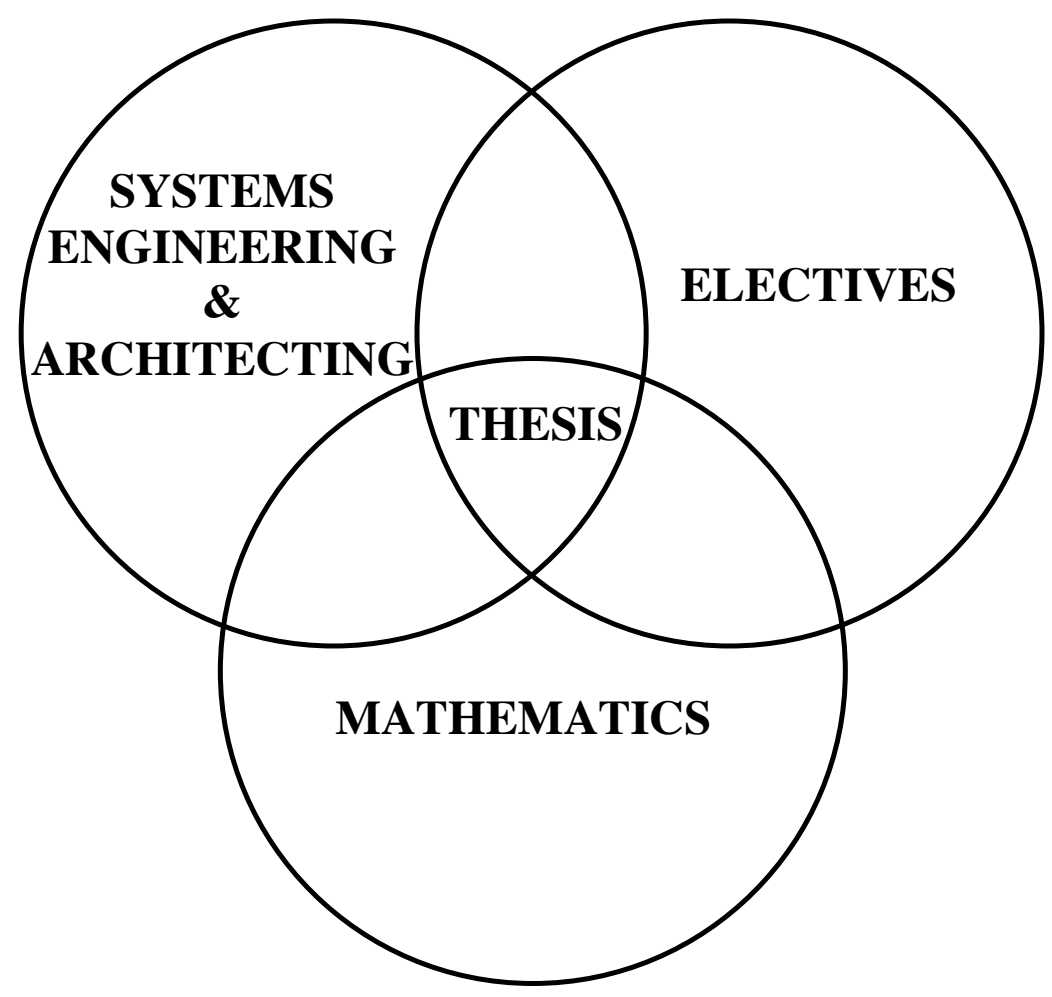

CONTEXT - Industrial Experience

Figure 1 - Representation of Aero-Astro Program in Aircraft Systems Engineering

The System Design and Management (SDM) program is designed to educate technically grounded leaders for enterprises concerned with complex products and systems. The degree therefore requires and builds upon strong disciplinary backgrounds with the curriculum stressing fundamentals through the teaching of relevant concepts and tools. The overall program, as represented in Figure 2, builds upon a curriculum that combines technical depth, delivered 
through a series of engineering and design electives, with engineering and management breadth, obtained through a suite of foundation courses ${ }^{5}$. This is structured around three system-oriented courses in system architecture, system engineering, and system and project management. These courses, along with further program experiences and thesis work, provide an integration of the disciplinary aspects through the system perspective central to the program. Various experiences and course engagements work to provide the leadership cap. As noted, a key part of the program is the thesis where the student addresses a combination of engineering and management issues. The work is practically oriented and generally rooted in current or past work experience.

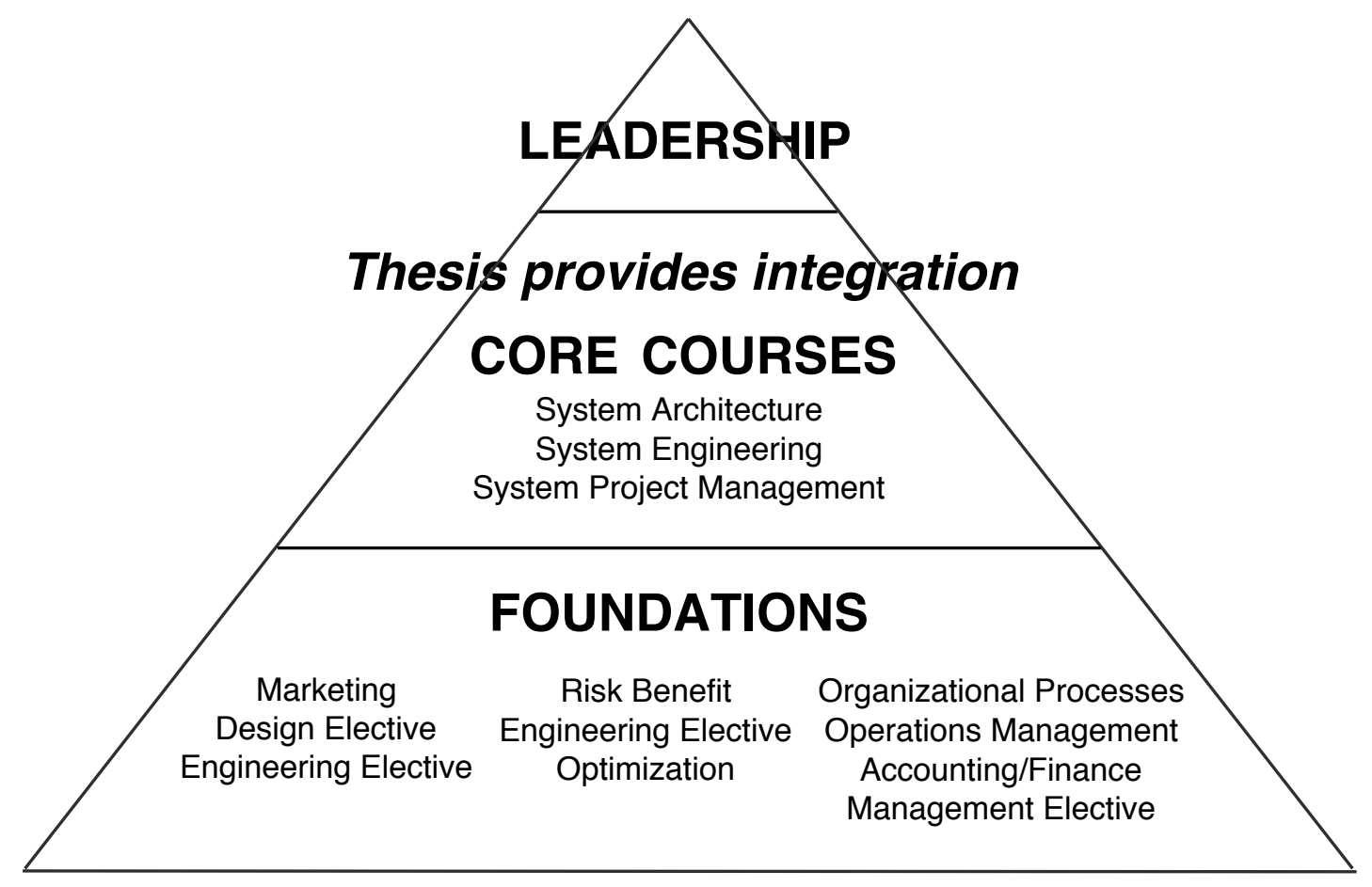

Figure 2 -- Representation of the SDM (System Design and Management) Program

The Leaders for Manufacturing (LFM) program is designed to teach students an appreciation for continuous, incremental improvement as well as for groundbreaking innovation - while providing the tools needed to accomplish both. The LFM academic program consists of 20+ courses, local plant tours and a two-week trip to facilities throughout the U.S., a 6.5-month internship and associated research culminating in a thesis, participation in LFM program management, and a two-year leadership sequence consisting of classes, seminars, and other activities. The overall representation of the program is shown in Figure $3^{6}$ and is similar in structure to the SDM program. Through this class work, research, and opportunities to lead and learn by doing, LFM students acquire a solid background in critical areas of "Big M" manufacturing, building upon a solid base of fundamentals, integrating through various experiences, internship, and key courses, and working leadership through the described sequence. The work leads to two degrees, one in management and one in a department within the School of Engineering. Students have academic advisors from both schools and thesis advisors from both schools. The primary work for their thesis is performed within their internship for a company involved in the program partnership and involves a team comprising the faculty 
advisors from the two schools, one or more advisors from the company, and the students. Often, program alumni/ae are involved from the companies where they have pursued further careers.

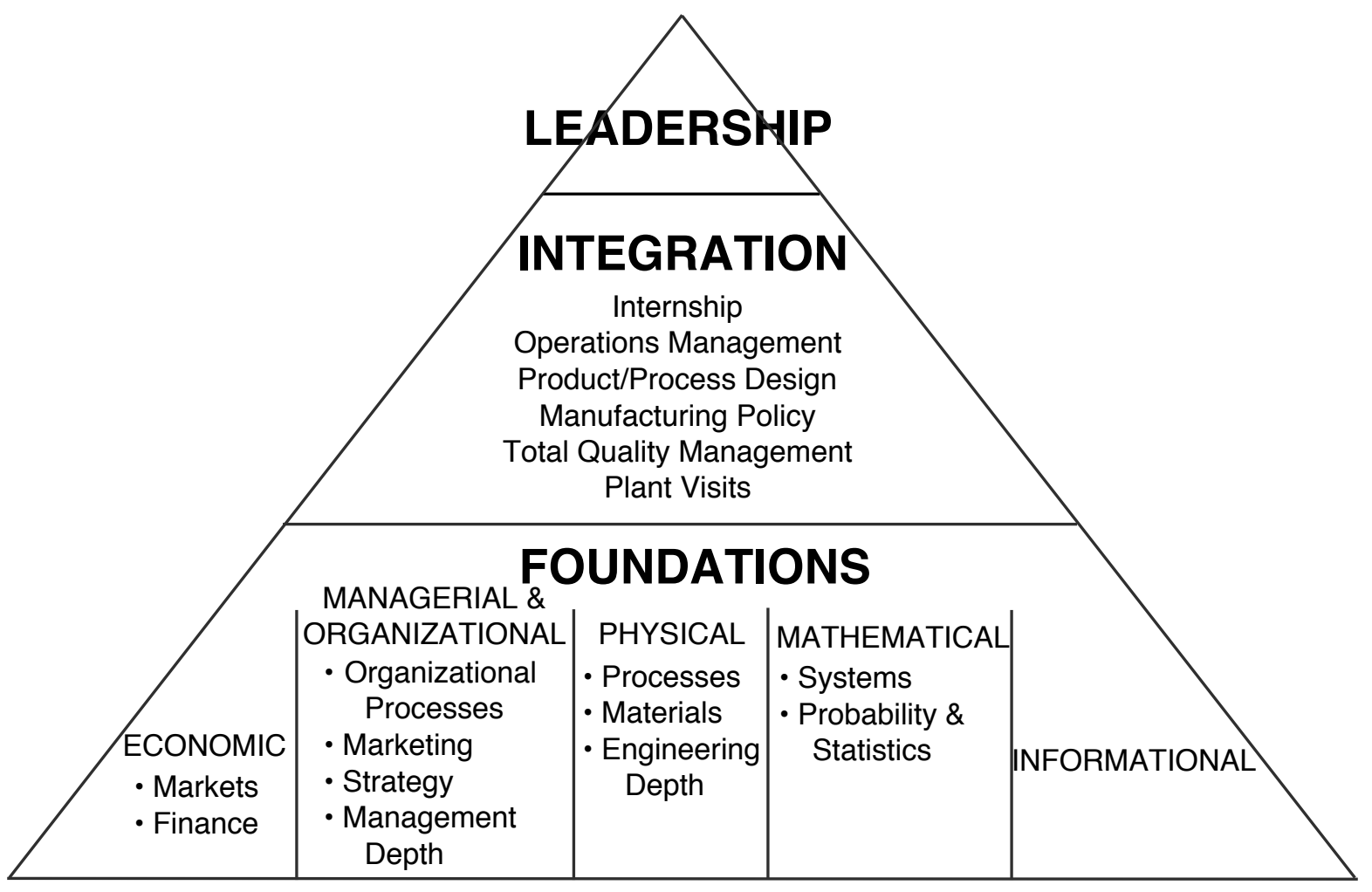

Figure 3 -- Representation of the LFM (Leaders for Manufacturing) Program

Subjects related to aircraft system design are offered in the Department of Aeronautics and Astronautics, the Engineering Systems Division, and/or the Sloan School of Management ${ }^{8}$. Table 1 lists the subjects most directly relevant to aircraft lifecycle design as well as the accessibility to students in the each of the three degree programs. Beyond these lay a vast array of disciplinary subjects in vehicle technologies (aerodynamics, propulsion, materials and structures, navigation and control), software engineering, air transportation, manufacturing, logistics, supply chains, management, economics, mathematics, and other relevant topics that often serve as elective subjects. The syllabus, lecture notes, and related material for some of these subjects are available through MIT's Open Courseware System? .

\section{Aircraft Systems Engineering Subject}

In considering the subjects listed in Table 1, it is apparent that only a few have been introduced to meet the specific needs of the aircraft systems engineering domain. One of these is Aircraft Systems Engineering which adopts a holistic view of the aircraft as a system, covering: basic systems engineering; basic aircraft performance and weight estimation; cost and financial analysis; safety and reliability; lifecycle topics; environmental factors; major aircraft subsystems; risk analysis and management; and system realization topics such as validation and verification (certification), manufacturing, and lean practices. Twenty-six lectures, many given by industry 
Table 1 - Selected Subjects Addressing Lifecycle Topics of Aircraft Design

\begin{tabular}{|l|c|c|c|}
\hline \multirow{2}{*}{\multicolumn{1}{|c|}{ Subject }} & \multicolumn{3}{c|}{ Accessible to Students in } \\
\cline { 2 - 4 } & Aero-Astro & SDM & LFM \\
\hline Aircraft Systems Engineering* & $\mathrm{X}$ & $\mathrm{X}$ & $\mathrm{X}$ \\
\hline Air Transportation System Architecting* & $\mathrm{X}$ & $\mathrm{X}$ & $\mathrm{X}$ \\
\hline System Architecting & $\mathrm{X}$ & $\mathrm{X}$ & $\mathrm{X}$ \\
\hline $\begin{array}{l}\text { Multidisciplinary System Design and } \\
\text { Optimization }\end{array}$ & $\mathrm{X}$ & $\mathrm{X}$ & $\mathrm{X}$ \\
\hline Product Design and Development* & $\mathrm{X}$ & $\mathrm{X}$ & $\mathrm{X}$ \\
\hline The Airline Industry & $\mathrm{X}$ & $\mathrm{X}$ & $\mathrm{X}$ \\
\hline Integrating the Lean Enterprise* & $\mathrm{X}$ & $\mathrm{X}$ & $\mathrm{X}$ \\
\hline System Safety* & $\mathrm{X}$ & $\mathrm{X}$ & $\mathrm{X}$ \\
\hline Engineering Risk-Benefit Analysis & $\mathrm{X}$ & $\mathrm{X}$ & $\mathrm{X}$ \\
\hline Engineering Systems Analysis & $\mathrm{X}$ & $\mathrm{X}$ & $\mathrm{X}$ \\
\hline System Engineering* & & $\mathrm{X}$ & $\mathrm{X}$ \\
\hline System and Program Management & & $\mathrm{X}$ & $\mathrm{X}$ \\
\hline System Dynamics & $\mathrm{X}$ & $\mathrm{X}$ & $\mathrm{X}$ \\
\hline Axiomatic Design & $\mathrm{X}$ & $\mathrm{X}$ & $\mathrm{X}$ \\
\hline Integrated Product and Process Design & $\mathrm{X}$ & $\mathrm{X}$ & $\mathrm{X}$ \\
\hline
\end{tabular}

* Subject material available from MIT's Open Courseware website ${ }^{9}$

and government subject matter experts, cover these listed topics. Each lecture is at the level of an introductory chapter to a book that would cover that subject area ${ }^{\mathrm{b}}$. In parallel with the lectures, students complete a detailed case study (subsequently described) of an existing aircraft. A day-long field trip to an aircraft manufacturing plant (e.g. Sikorsky aircraft) provides an additional learning element. There are no prerequisites for the subject and the students have varied backgrounds. Yet, they are able to gain introductory level knowledge of all these topics, and at the same time see the interconnections of the full range of disciplines that pertain to an aircraft system. The course has been offered three times to a total of 40 students from the three degree programs described.

Borrowing on pedagogy from architecture, the course adopts retrospective analysis through detailed case studies of existing aircraft systems. A large part of an architect's design education is based upon analysis of existing buildings, complexes of buildings, or layouts of large spaces in working to develop an understanding of the design drivers, key design decisions, and the resulting success of the design in meeting the needs of the multiple stakeholders. Retrospective analysis has not been widely used in engineering, yet it provides a sound pedagogic approach to understand the design of complex systems involving technical, social, and lifecycle features. Small student teams select an aircraft from a list offered by the faculty, and several structural elements for the semester long case study help their execution. The faculty arrange for a subject matter expert (SME) knowledgeable about the early phases of the program to be a resource for

\footnotetext{
${ }^{\mathrm{b}}$ Many of these lectures can be downloaded from http://ocw.mit.edu/OcwWeb/Aeronautics-and-Astronautics/16885JFall2003/CourseHome/index.htm
}

Proceedings of the 2005 American Society for Engineering Education Annual Conference \& Exposition. Copyright (C) 2005, American Society for Engineering Education. 
the students. The students are expected to find most of the resource material from publicly available sources. However the faculty or SME can often assist in making connections with the company or other SMEs to obtain non-proprietary data and reports. The written case study is developed in a spiral process with four successive versions during the semester, each one adding new material while responding to critiques of earlier drafts by faculty and/or the SMEs. Each team also gives two oral presentations so that the other students learn something from each case study. The result is a comprehensive document, about 100 pages in length, covering all aspects of the origins, design, system and subsystems descriptions, production, sales, operation, and, as appropriate, derivatives/upgrades/retirement of the aircraft. Case studies have been completed for the B-52, B-777, DC-9, F-111, F-117A, F-14, F-16, Citation X and G-IV ${ }^{\mathrm{c}}$.

The case studies serve as valuable reference documents for teaching and research. As an example, consider the data on lifecycle aspects extracted from four of the case studies and presented in the Appendix. For these aircraft, the operational lives span 32 to 75 years, while the development time ranged from 33 to 77 months: a factor of 12 difference in time scales. Although these aircraft differ in their origins, missions or markets, and customers, there are several common features that emerge regarding design practices for achieving lifecycle value, such as:

- A focus on the "ilities" such as affordability (low acquisition cost, low operational cost), simplicity (e.g., low part count, modularity, part commonality), reliability, availability or dispatchability, maintainability

- Use of evolutionary upgrades and derivatives, and/or modular architectures to incorporate new technology or to address new missions/markets.

- Engine capability as an enabler of evolving aircraft capability.

These features are familiar to those versed in design for lifecycle value, but it is interesting to see how they naturally emerge from the retrospective analysis case studies. This provides an excellent way for students to comprehend the importance of, and approaches for, DFX. Many other lessons about aircraft design can be extracted from these case studies. For example, the importance of organizational structures such as integrated product teams to bring knowledge from lifecycle phases into design, or the importance of understanding and incorporating the customer and other stakeholder lifecycle expectations into the design.

\section{Observations}

In recent years, the authors have been involved to some degree with the establishment or leadership of the three degree programs summarized in the preceding section, and in developing or teaching part of the curriculum. Rather than further detailing the specific content and outcomes of the subjects, the authors share their overall "lessons learned" from developing and offering graduate-level curriculum on aircraft systems engineering, highlighting the observations that are most relevant to addressing lifecycle issues. Seven observations discussed in this section broadly fall into the following categories:

- Accessing the Body of Knowledge (BOK) supporting the curriculum

- Developing faculty competency and collaboration

- Pedagogy

${ }^{\mathrm{c}}$ Copies of the case studies may be obtained by contacting the first author at murman@mit.edu

Proceedings of the 2005 American Society for Engineering Education Annual Conference \& Exposition. Copyright (C) 2005, American Society for Engineering Education. 
- Synergies between teaching, research and practice

- The learning community

The authors strongly believe that these observations, which emerged from the development and offering of the curriculum related to lifecycle aspects of aircraft design, have general relevance for those considering or involved in the development of such offerings.

Broadly speaking, aircraft system design could be said to rest upon two bodies of knowledge (BOK) - engineering sciences and engineering practice. The first relies on knowledge emerging from physics, chemistry, mathematics, and other sciences while the second relies on knowledge emerging from actual aircraft system programs. One can access the BOK in the first category through laboratory experimentation, numerical techniques, and analysis. Although industrial input is important for focusing on critical issues, by and large academics can become proficient in most of the engineering science disciplines without significant industrial experience. This is in sharp contrast to the second category of engineering practice where exposure to industry is essential to developing the BOK and faculty competency. Topics such as safety, understanding stakeholder needs, design for \{manufacturing, assembly, maintainability, operation, certification, etc.\}, lifecycle cost estimation, and risk management do not stem from Newton's laws, the laws of thermodynamics, and similar foundations familiar to aerospace engineers. These topics rest upon experience gained from many programs, and often rely upon heuristics and other codified knowledge that cannot be derived from a few fundamental principles. Frequently, the knowledge cannot be represented in symbolic form and, therefore, analytical modeling may not be available. For these reasons, substantive linkage with industry is absolutely essential to developing and deploying curriculum relevant to aircraft system design. It is important that both industry and academia recognize the need to develop partnerships to advance the academic discipline of aircraft system design. Research projects are needed to extract and codify knowledge bases, industrial participation is needed for identifying meaningful design problems, subject matter experts are needed for guest lecturers and case study experts, and meaningful industrial exposure is needed to develop faculty competency.

This latter point leads to the next observation that the nature of faculty competency needed for developing and deploying aircraft systems design curriculum is different than that for most of the disciplines represented in aerospace engineering departments. It requires a blending of basic engineering science knowledge with the experience knowledge of actual engineering practice. Moreover these need to be combined with the educational knowledge, experience, and capability to properly present these aspects and help students to learn the knowledge and begin to develop the associated capability. Perhaps the simplest path is to hire accomplished aircraft designers as faculty members to fill the void and to work with them in the academic and classroom environment. Indeed, for many schools this is the chosen route and it works well when the right person is available. It is, however, of key importance to help this person adapt to the culture of the academic environment and to learn to interface with, and address the needs of, the learning community of students. Nevertheless, even when these details are given the needed attention, this approach is only a partial solution to a systemic shortcoming of the current academic generation - by and large, they lack practical experience.

Looking upon the field of medicine as an example, a typical faculty member divides their time approximately equally between teaching, researching, and practicing medicine. If such a balance 
could be achieved in aerospace engineering, not only would faculty be better prepared to teach system design, but they also would better understand the practical import of their research and teaching in their disciplinary specialties. One outstanding attempt to address this imbalance is The Boeing Company's A.D. Welliver Faculty Fellow Program ${ }^{10}$. This has provided over 100 faculty members a summer internship to understand and reflect upon how the modern practice of engineering can be incorporated into their academic strategy. Unfortunately, other companies have not demonstrated the same vision to work with academia to bridge the knowledge gap through fellowship or internship programs. The authors of this paper have been fortunate to be associated with three MIT programs with major industrial participation: Leaders for Manufacturing $^{5}$, System Design and Management ${ }^{6}$, and the Lean Aerospace Initiative ${ }^{11}$. Through these, and other opportunities to interact with industry, the authors have developed an appreciation and a level of competency that permits them to participate in the undertakings covered in this paper. Whether it be through the Welliver program or other routes, faculty need to spend substantial time working in or with industry to develop the competency to participate in aircraft system design curriculum. Clearly, there also are faculty incentives for promotion and tenure that need to be adjusted to support this imperative. Such are beyond the control of individual faculty, and often beyond the control of their Department Heads. Addressing this requires substantial dialog and concerted action at least at the level of Deans. However, faculty who seek to participate in this arena should not wait for resolution of this matter. The authors and others of their colleagues have enjoyed interesting and challenging experiences and have not been adversely impacted by out-of-kilter incentive systems.

In addition to the competency of the faculty, the composition of the faculty needed to teach aircraft systems design needs consideration. There may be a few gurus who can span the intellectual spread represented by the topics in the previous section. However, these people will always be few and far between. Just as the design of an aircraft system relies on multifunctional teams, so does the teaching of aircraft systems design. Engineering faculty who teach aircraft systems design need to work collaboratively with other engineering faculty, management faculty, and industrial practitioners to develop and deploy meaningful curriculum. Such experts often have different ways of thinking about issues and different expectations for outcomes. Sometimes the languages used are different. Uniting on a commonly shared goal can provide a focus for a successful undertaking as well as provide a model of the needed team approach for the students involved. The authors have found such collaborations very stimulating, and often more creative than those centered on more narrow disciplinary topics.

The material involved in system design courses differs substantially from that involved in traditional engineering discipline subjects. In the latter, there are many equations that define phenomena and associated simple models that can be used. This allows the establishment of straightforward problems to work and absolute answers associated with such. In regard to engineering systems, there are few, if any, simple models to represent their behavior. Because of this, traditional homework or quiz problems familiar to engineering science subjects are not possible. Furthermore, whereas the foundations of traditional engineering disciplines are based upon fundamental laws and enriched by ever-accumulating knowledge building upon them, engineering systems disciplines are based upon continually evolving best practices. This requires a different culture of teaching and thus, the pedagogy used for effectively teaching lifecycle topics for aircraft system design needs to be substantially different from traditional 
engineering discipline subjects. For example, meaningful assignments need to address real system issues, which are often best addressed through case studies - a pedagogy not familiar in engineering. Given the academic unit of "a subject" usually spanning a semester/quarter or two, it is challenging to have the students experience the entire lifecycle from conception to operation through a design problem. Pedagogies are needed which emulate many years of on-the-job learning of systems engineers. The retrospective analysis approach, as described earlier for the Aircraft Systems Engineering subject, is one example of a new pedagogy. Further experimentation by multiple institutions and the sharing of their experiences would be helpful for developing more effective pedagogical strategies for teaching the lifecycle aspects of aircraft system design.

The requirements for effective pedagogy naturally lead to closer linkages between the classroom and practice. Lectures, assignments, case studies, and class projects are intimately linked to evolving industrial practice and examples. For example, assignments often center on analyzing real problems drawn from industrial examples. Furthermore, class products are closer to real products than they are in the traditional model problems of engineering science subjects. This leads to an emergent finding that a significant synergy between teaching, research, and practice exists and can be exploited and leveraged in a number of ways in the development and delivery of system subjects. For example, one faculty member who has been teaching System Architecture for several years now has a substantial database of product architectures contributed by his students from their assignments, a resource that would have taken many case studies or theses to develop. In another course, the semester-long class design project was delivered to a real customer and also published as a professional society paper ${ }^{12}$. Industrial students in these subjects can quickly apply what they learn in lecture or assignments to their current jobs. This not only translates recent knowledge from the faculty into practice, but also provides immediate feedback to the faculty for further research or to include in future lectures. In the case of internships, new knowledge is applied and discovered from and through a team involving all parts of these programs -- students, industry members, and faculty. Another factor is that the strong linkages with industry in developing and delivering the curriculum naturally lead to interactions between teaching, practice, and research. Identified gaps of knowledge lead to ideas for new research studies, and this and the overall work help set priorities for future work.

The background of students the authors have taught in some of the subjects listed earlier differs substantially from those found in a traditional aerospace engineering graduate program centered on research degree tracks. On one end of the spectrum have been students who have just received a bachelors degree, many of whom have no industrial design experience, and some from foreign programs with no capstone design course. At the other end of the spectrum have been practicing industry engineers with considerable experience, some taking the course through distance-learning technology from their workplace. Some students have never taken a course that didn't have analytical homework problems. Other students have little patience for conceptual material that cannot be directly applied. The wide spread of student backgrounds has been both a challenge and an opportunity. The diversity of student backgrounds can be properly exploited to lead to a rich learning community where less experienced students learn from seasoned practitioners, who themselves learn by teaching. Two examples illustrate this point. In a lecture on risk management, distance-learning students added personal anecdotes as to the importance of consistently using even the simplest of risk management tools, which first-year 
students thought to be almost trivial due to their simplicity. Turning the tables, research-oriented graduate students are able to bring updated technology they have learned to their teams whose industry students may not have as direct exposure.

In the SDM and LFM programs, the student learning community continues beyond the degree studies. Students who have graduated often continue to play various roles in regard to these programs. They return to participate in the program by contributing knowledge they have acquired in their industry experience. Furthermore, they quickly realize that the learning they have done within these programs is not enough in the ever-changing world of systems and they need to acquire new and evolving knowledge. Just as there are lifecycle phases to the product, there are special demands in regard to lifecycle learning, and alumni/ae can play key dual roles of lifelong students and lifelong teachers. These graduates represent a rich pool of continually developing and new knowledge with regard to engineering practice and this can be leveraged in a number of ways. These practicing graduates can be brought into the classroom to share their acquired knowledge with today's students. This new knowledge can also be an important lifelong learning target for faculty and these alumni/ae can help in reshaping courses and overall curricula. The alumni/ae can also be brought together to share knowledge with each other. Both the LFM and SDM Programs have developed strong alumni/ae programs where this sharing occurs and builds on itself. This also finds its way back into the classroom and research studies reinforcing the synergy between teaching, research, and practice.

\section{Summary}

Aircraft systems design curriculum spans a wide spectrum of disciplines covering technical, social, and lifecycle topics. Such curriculum is appropriate for graduate masters-level studies. Three MIT degree programs in the Department of Aeronautics and Astronautics and Engineering Systems Division offer opportunities and subjects for students seeking such curriculum.. A core subject on Aircraft Systems Engineering adopts the pedagogy of retrospective analysis of existing aircraft systems to help students learn about design for best lifecycle value. Based upon recent experience the authors have had on developing and delivering curriculum related to the lifecycle aspects of aircraft systems design, the following observations are offered:

- Substantive linkage with industry is absolutely essential to developing and deploying curriculum relevant to aircraft system design.

- Faculty need to spend substantial time working in or with industry to develop the competency to participate in aircraft system design curriculum.

- Engineering faculty who teach aircraft systems design need to work collaboratively with other engineering faculty, management faculty, and industrial practitioners.

- The pedagogy used for effectively teaching lifecycle topics for aircraft system design needs to be substantially different from traditional engineering discipline subjects.

- A significant synergy between teaching, research, and practice exists and can be exploited and leveraged in a number of ways in the development and delivery of system subjects.

- The diversity of student backgrounds can be properly exploited to lead to a rich learning community where less experienced students learn from seasoned practitioners, who themselves learn by teaching. 
- There are special demands in regard to lifecycle learning, and alumni/ae can play key dual roles of lifelong students and lifelong teachers.

It is hoped that these observations will contribute to further sharing of information and dialog among academic and industry stakeholders interested in further advancing the topic of this paper.

\section{Acknowledgements}

Many MIT colleagues in engineering and management, and many from industry and government have contributed to the development of the curriculum reported in this paper and to the development of the authors' knowledge. Without attempting to list names, the authors acknowledge all of them. Several in particular who have shaped the Aircraft Systems Engineering subject deserve recognition: Al Haggerty, John Hansman, Bob Liebeck.

\section{References}

1. Murman, E. and Allen, T., "Engineering Systems: An Aircraft Perspective", MIT Engineering Systems Division Symposium, Mar 29-31, 2004

1. Fabrycky, W. and Blanchard, B., (1991). Life-cycle Cost and Economic Analysis, Prentice-Hall

1. http://web.mit.edu/aeroastro/www/

1. http://esd.mit.edu/

1. http://sdm.mit.edu/

1. http://lfm.mit.edu/

1. Murman, E.M, Clarke, J.P. and Hansman, R.J., "Aircraft and Air Transportation Systems Curriculum at MIT”, ICAS 2004, Yokohama, Japan, Aug 2004

1. For specific subject listings, see http://student.mit.edu/@2336120.26478/catalog/index.cgi

1. http://ocw.mit.edu/index.html

1. http://www.boeing.com/companyoffices/pwu/fellowship/objective.html

1. http://lean.mit.edu

1. Carreras C, et al. The Case For A Practical Small Supersonic Transport. 23rd International Congress of the Aeronautical Sciences, Toronto, Canada, 2002

\section{Author's Biographies}

\section{EARLL M. MURMAN}

Prof. Murman's interests include aircraft systems engineering, aerodynamics, and engineering education. From 1990-1996 he served as Head of MIT's Department of Aeronautics and Astronautics. In addition to his 25 years on the MIT faculty, he worked 10 years in industry and 3 years at NASA. He is a member of ASEE, NAE, INCOSE and an AIAA and RAeS Fellow.

\section{PAUL A. LAGACÉ}

Prof. Lagacé's interests include structural mechanics, advanced technology composites, manufacturing, engineering systems, particularly issues related to safety, and engineering education. He served as Co-Director of the Leaders for Manufacturing and Systems Design and Management Programs, and in leadership positions in the Department of Aeronautics and Astronautics and the Engineering Systems Division. He is a member of ASEE, a fellow of the AIAA, and a World Fellow of Composites of ICCM. 


\section{Appendix - Lifecycle Aspects Extracted from Four Case Studies}

\begin{tabular}{|c|c|c|}
\hline $\begin{array}{c}\text { Aircraft and } \\
\text { Key Lifecycle Statistics }\end{array}$ & $\begin{array}{c}\text { Prominent Lifecycle } \\
\text { Considerations During } \\
\text { Development \& Manufacturing }\end{array}$ & $\begin{array}{c}\text { Prominent Lifecycle Aspects } \\
\text { During Operation and } \\
\text { Product Upgrade }\end{array}$ \\
\hline $\begin{array}{l}\text { B-52 }^{1} \\
\text { Models A-H } \\
\text { Units produced: } 744 \\
\text { Development time*: } 77 \text { mos } \\
\text { Expected operational life for } \\
\text { Model H: } 75 \text { yrs }\end{array}$ & $\begin{array}{l}\text { - Little emphasis on lifecycle } \\
\text { consideration during design } \\
\text { - Design emphasized simplicity } \\
\text { - Design evolved with needs, and } \\
\text { knowledge from early models } \\
\text { incorporated into later models. }\end{array}$ & $\begin{array}{l}\text { - Mission evolved from long range } \\
\text { strategic bomber and } \\
\text { reconnaissance to: } \\
\text { o Air-ground missile, cruise } \\
\text { missile, and smart weapons } \\
\text { launch } \\
\text { o Conventional bomber } \\
\text { o Low level penetrator } \\
\text { o Special payloads launch } \\
\text { - Significant avionics upgrades } \\
\text { throughout platform life } \\
\text { - Lifetime extension enabled by low } \\
\text { usage in later life. }\end{array}$ \\
\hline $\begin{array}{l}\text { DC-9 }^{2} \\
\text { Models 10, 20, 30, } 40 \\
\text { Units produced: } 976 \\
\text { Development time*: } 33 \text { mos } \\
\text { Expected operational life: } 45 \text { yrs }\end{array}$ & $\begin{array}{l}\text { Design emphasized } \\
\text { - Reliability } \\
\text { - Maintainability } \\
\text { - Dispatchability }(99 \%) \\
\text { - Manufacturability (low part count) } \\
\text { - Low DOC ( } \$ 1 / \mathrm{mi} 1962 \text { dollar) }\end{array}$ & $\begin{array}{l}\text { - P\&WJT8D engine allowed for } \\
\text { growth models } 20,30,40 \\
\text { - MD-8X/9X/B-717 derivatives sold } \\
\text { approximately } 1475 \text { units } \\
\text { - Product reliability and cost } \\
\text { effectiveness contributed to long } \\
\text { lifecycle. }\end{array}$ \\
\hline $\begin{array}{l}\text { F-14 } \\
\text { Models A, B, D } \\
\text { Units produced: } 773 \\
\text { Development time*: } 48 \text { mos } \\
\text { Expected operational life: } 32 \text { yrs }\end{array}$ & $\begin{array}{l}\text { Design emphasized } \\
\text { - Maintainability } \\
\text { - Reliability } \\
\text { - Supportability }\end{array}$ & $\begin{array}{l}\text { Engine upgrade led to drastic } \\
\text { reduction in aircraft losses } \\
\text { - Ground attack role added } \\
\text { - Being retired due to high } \\
\text { maintenance costs from aging } \\
\text { systems }\end{array}$ \\
\hline $\begin{array}{l}\text { F-16 }^{4} \\
\text { Models A/B (Blocks 0,1,5,10,15) } \\
\text { Models C/D (Blocks 25, 30/32. } \\
\text { 40/42, 50/52, 60) } \\
\text { Units produced: >4300 } \\
\text { Development time*: } \\
\quad 31 \text { mos for prototype } \\
\quad 73 \text { mos for full scale dev. } \\
\text { Expected operational life: } \\
\quad 40 \text { yrs for U.S. } \\
\quad 50 \text { yrs for other countries }\end{array}$ & $\begin{array}{l}\text { - Design emphasized } \\
\text { o Simplicity } \\
\text { o Maintainability } \\
\text { o Reliability } \\
\text { o Commonality } \\
\text { o Low cost } \\
\text { - Designed with modular, open } \\
\text { architecture } \\
\text { - Long production run and modular } \\
\text { architecture led to evolution in } \\
\text { manufacturing and design }\end{array}$ & $\begin{array}{l}\text { - Multinational Staged } \\
\text { Improvement Program enabled } \\
\text { product evolution through block } \\
\text { upgrades } \\
\text { - Large customer base has enabled } \\
\text { continual technical upgrade } \\
\text { - Evolved from fighter to multi-role } \\
\text { aircraft including air-ground, air } \\
\text { defense, night/precision attack, } \\
\text { enemy air defense suppression and } \\
\text { other missions. } \\
\text { - Product has been cost effective, } \\
\text { reliable, \& effective. }\end{array}$ \\
\hline
\end{tabular}

* Development time defined as program go-ahead to initial operational capability of first model.

Case studies from MIT Course 16.885J Aircraft Systems Engineering

1. Barter, G, Jonker, K., Poon, A., Tan, D., Weiss, K., “The B-52 Stratofortress: A Case Study”, Dec, 2003

2. Atherton, M., Klima, K., Plas, A., "DC-9: A Case Study", Dec, 2004

3. MacKenzie, S., Parker, D., Patel, S., Shinagawa, Y., "F14 Tomcat: A Systems Case Study", Dec, 2004

4. Capozzoli, P., Deremaux, Y, Ferdowsi, B., Kountras, A., Schuman, T., "F-16 Fighting Falcon: A Case Study", Dec, 2002 